Jurnal Media Analis Kesehatan, Vol. 8, No.2, November 2017

http://journal.poltekkes-mks.ac.id/ojs2/index.php/mediaanalis

e-ISSN : 2621-9557

p-ISSN : 2087-1333

\title{
ANALISIS HUBUNGAN GRADASI BASIL TAHAN ASAM DENGAN INDEKS ERITROSIT PADA PENDERITA TUBERCULOSIS DI BALAI KESEHATAN PARU MASYARAKAT MAKASSAR
}

\author{
Mursalim $^{1}$, Johnny Angky ${ }^{2}$ \\ ${ }^{1}$ Jurusan Analis Kesehatan Poltekkes Kemenkes Makassar \\ ${ }^{2}$ Jurusan Keperawatan Gigi Poltekkes Kemenkes Makassar
}

\begin{abstract}
ABSTRAK
Tuberculosis dapat menimbulkan kelainan hematologi, baik sel-sel hematopoiesis maupun komponen plasma. Kelainan-kelainan tersebut sangat bervariasi dan kompleks. Kelainan hematologis ini dapat merupakan bukti yang berharga sebagai petanda diagnosis, pentunjuk adanya komplikasi atau merupakan komplikasi obat anti tuberculosis (OAT). Rumusan masalah dalam penelitian ini adalah seberapa besar indeks eritrosit pada penderita tuberculosis, apakah ada hubungan basil tahan asam 1+ dengan indeks eritrosit, apakah ada hubungan basil tahan asam 1+ dengan indeks eritrosit, Apakah ada hubungan basil tahan asam 3+ dengan indeks eritrosit, dan apakah ada hubungan gradasi basil tahan asam dengan indeks eritrosit. Jenis penelitian ini adalah penelitian bersifat analisis yang bertujuan untuk mengetahui hubungan gradasi basil tahan asam dengan indeks eritrosit rata-rata pada penderita tuberculosis diagnosis awal. Hasil penelitian menunjukkan bahwa jumlah indeks eritrosit pada penderita tuberculosis di BBKPM Makassar yaitu pada tabel 4.4 yaitu dengan rerata MCV sebanyak 79,55, MCH 29,05, dan MCHC 30,72, pada tabel 4.6 Ada hubungan indeks eritrosit pada penderita tuberculosis dengan gradasi 1+, pada tabel 4.8 ada hubungan indeks eritrosit pada penderita tuberculosis dengan gradasi $2+$, pada tabel 4.10 ada hubungan indeks eritrosit pada penderita tuberculosis dengan gradasi $3+$ dan pada tabel 4.11 ada hubungan indeks eritrosit pada penderita tuberculosis dengan gradasi basil tahan asam. Oleh karena itu disarankan pada penelitian selanjutnya dilakukan penelitian tentang sejauh mana pengaruh indeks eritrosit khususnya anemia terhadap penderita TB dan jenis Anemianya.
\end{abstract}

Kata Kunci: Gradasi BTA, Indeks eritrosit, MCV, MCH, MCHC

\section{PENDAHULUAN}

Penyakit Tuberculosis (Tb) paru adalah suatu penyakit infeksi, penyakit kronis, penyakit menular langsung, yang dapat menyerang siapa saja terutama mereka yang tinggal di dalam rumah yang lembab dan ventilasi udara yang tidak baik serta orang-orang yang daya tahan tubuhnya rendah. Tuberculosis terutama menyerang paru-paru, dan juga dapat menyerang organ lain diluar paru dikenal sebagai $\mathrm{Tb}$ ekstra paru. (Misnadiarly, 2006).

Tuberculosis ( $\mathrm{Tb})$ merupakan penyakit yang mudah menular dan salah satu penyakit infeksi yang menjadi 
masalah kesehatan masyarakat utama di Negara-negara berkembang. Diperkirakan sepertiga penduduk dunia telah terifeksi kuman $\mathrm{Tb}$ dan $90 \%$ diantaranya penderita malah berada di Negara berkembang. World Health Organization( WHO ) membuat daftar hingga 22 high burden countries, dan Indonesia menduduki urutan ketiga setelah India dan Cina. Sekitar $25 \%$ dari seluruh kematian di dunia disebabkan oleh penyakit $\mathrm{Tb}$ dan sekitar $80 \%$ kematian tersebut berasal dari kelompok usia produktif. Di sulawesi selatan 18.000 penderita $\mathrm{Tb}$ di 23 kabupaten/kota ini sangat memperihatinkan apalagi di makassar penderitanya 1532 orang (Kusnadi, 2010).

Berdasarkan data WHO, setiap tahun sekitar delapan sampai sepuluh juta kasus tuberkulosis baru dilaporkan diseluruh dunia, dan dua juta orang dewasa meninggal karena penyakit ini. Sebagian besar kasus (95\%) dan kematian $(98 \%)$ terjadi di negara-negara miskin. Tuberkulosis dapat melibatkan berbagai sistem organ ditubuh.

Penderita pada umumnya datang dengan tanda dan gejala klinik hematemesis melena, pucat, dan anemia. Pada kondisi tertentu keadaan ini dapat diatasi secara konservatif. Kuman Tb menyerang jaringan paru ini dapat menimbulkan kerusakan kapiler paru dapat menimbulkan pendarahan. Pendarahan dari jaringan paru ini dapat menimbulkan gejala batuk darah segar atau muntah darah, darah yang di muntahkan berupa darah hitam karena terkontaminasi asam lambung.

Tuberculosis dapat menimbulkan kelainan hematologi, baik sel-sel hematopoiesis maupun komponen plasma. Kelainan-kelainan tersebut sangat bervariasi dan kompleks. Kelainan hematologis ini dapat merupakan bukti yang berharga sebagai petanda diagnosis, pentunjuk adanya komplikasi atau merupakan komplikasi obat anti tuberculosis (OAT). Kelainan hematologis ini dapat juga menimbulkan kesulitan dalam pengelolaan tuberculosis karena akan mempengaruhi pemilihan (OAT). OAT juga dapat menimbulkan banyak efek samping kelainan hematologis. (Amaylia Oehadian, 2003).

Secara laboratoris, anemia dijabarkan sebagai penurunan kadar hemoglobin serta hitung eritrosit dan hematokrit di bawah normal. Serta di perlukan pemeriksaan indeks eritrosit diantaranya MCV (Mean Corpuscular Volume), MCH (Mean Corpuscular hemoglobin), dan MCHC (Mean Corpuscular Hemoglobin Concentration) sebagai penunjang. (Handayani, 2008).

Pemeriksaan indeks eritrosit pada penderita $\mathrm{Tb}$ paru yaitu untuk mengetahui jenis anemia, di mana anemia adalah kumpulan gejala yang ditandai dengan kulit dan membran mukosa pucat dan pada tes laboratorium diidapatkan hitung hemoglobin $(\mathrm{Hb})$, Hematokrit (Hm), dan eritrosit kurang dari normal. Sehingga penderita Tb paru sering terkena anemia.

Asupan yang tidak adekuat ditambah dengan terjadinya infeksi tuberculosis dapat memicu malnutrisi serta memperparah kondisi infeksi tuberculosis. Pada pasien dengan tuberculosis, terjadinya penurunan nafsu makan, perubahan pola makan, 
malabsorbsi zat gizi, dan perubahan metabolisme dapat mengakibatkan wasting. Dalam berbagai studi menunjukkan bahwa penderita tuberculosis memiliki status gizi yang lebih rendah daripada kelompok kontrol sehat (Brugnara C, 2003).

Tuberculosis sebagai penyakit kronis dapat menyebabkan beberapa komplikasi yaitu anemia, hiponatremia,leukositosis, abnormalitas fungsi hepar,hipokalsemia,dan peningkatan sedimen eritrosit (Oyer,1994 )

Anemia secara fungsional didefinisikan sebagai penurunan massa eritrosit dengan akibat oksigenasi jaringan tidak dapat terpenuhi , beberapa jenis anemia yang ada pada pasien Tuberculosis yaitu anemia penyakit kronis,merupakan salah satu penyebab tersaring anemi pada penderita ( Fleming etal,2003 ).

$\begin{array}{ccc}\text { Sosial } & \text { Ekonomi sanga } \\ \text { berpengaruh } & \text { pada } & \text { tingka }\end{array}$
komsumsi.komsumsi dan asupan makanan yang tidak mencukupi biasanya menyebabkan keadaan gizi kurang,sehingga mempermudah masuknya bibit penyakit kedalam tubuh dan menyebabkan penyakit infeksi.Asupan gizi makro dari penderita tuberculosis paru masih sangat kurang yang akan berpengaruh pada peningkatan kesembuhan dan status gizi penderita adanya peningkatan asupan makanan pada penderita tuberkulosis paru akan meningkatkan status gizi (Hizira, 2008).

Anemia pada tuberculosis dapat dikarenakan terjadinya gangguan pada proses eritropoesis oleh mediator inflamasi, pemendekan masa hidup eritrosit, gangguan metabolisme besi, adanya malabsorbsi dan ketidak cukupan zat gizi dikarenakan rendahnya nafsu makan. Baik anemia penyakit kronik maupun anemia defisiensi besi dapat terjadi pada penderita tuberculosis, dan anemia normokromik normositik merupakan jenis anemia yang paling sering ditemui pada penderita tuberculosis(Purnasari. Galih, 2011).

Tujuan penelitian adalah untuk mengetahui hubungan gradasi basil tahan asam dengan indeks eritrosit pada penderita tuberculosis diagnosis awal.

\section{METODE \\ Jenis dan Lokasi}

Jenis penelitian adalah penelitian korelasional. yang bertujuan untuk mengetahui hubungan gradasi basil tahan asam dengan indeks eritrosit ratarata pada penderita tuberculosis diagnosis awal. Penelitian direncanakan dilakukan di Balai Besar Kesehatan Paru Masyarakat Makassar (BBKPM).

\section{Populasi, Sampel, Teknik Pengambilan sampel, Alat dan Bahan} Populasi dalam penelitian ini adalah semua penderita tuberculosis yang melakukan pemeriksaan di Balai Besar Kesehatan Paru Masyarakat Makassar. Sampel Penelitian adalah penderita tuberculosis yang rawat jalanil selama berlangsungnya penelitian sebesar sampel adalah 30 (tiga puluh) sampel, dengan teknik pengambilan purposive sampling. Kriteria Inklusi yaitu penderita tuberculosis yang memiliki hasil basil tahan asam positif dan pasien rawat jalan. Kriteria Ekslusi yaitu penderita tuberculosis yang hasil basil tahan asam negatif dan pasien 
rawat inap. Alat yang digunakan antara lain tabung penampung darah, Karet pembendung/terniquet, Karet penghisap, Spoit 3 cc, Kamar hitung improved Neubauer, Pipet thoma, Tabung pengencer hemometer, Mikroskop, Pipet Hemoglobin, Batang Pengaduk, Standar Hb, Tabung mikrokapiler, Skala, Sentrifuge mikrokapiler, Bahan penutup khusus Objek gelas/ Slide, Ose/lidi, Lampu Spiritus, Pola, Korek api. Bahan yang digunakan diantaranya kapas alcohol, Sampel darah, Anti koagulan EDTA, Larutan Hayem, HCL 0,1 N, Aquadest, Sputum / Dahak, Reagen pewarnaan ZN.

\section{Cara Pengambilan Sampel dan Prosedur Kerja}

Disiapkan alat dan bahan yang digunakan, Dilakukan pembendungan pada lengan pasien dengan menggunakan karet pembendung, Disinfeksi bagian vena yang akan ditusuk dengan kapas alkohol $70 \%$, Ditusuk vena kemudian tarik semprit secara pelan - pelan sampai didapat volume darah sesuai kebutuhan yang diinginkan, Darah dimasukkan kedalam tabung yang sudah berisi EDTA kemudian homogenkan,Diberikan label pada tabung tersebut.

Cara kerja pemeriksaan Indeks Eritrosit Autometik:

Dihidupkan alat dengan menekan power pada cpu dan nyalakan computer kemudian nyalakan alat dengan menekan Switch utama yang terletak disamping kanan instrument. Setelah lampu indikator menyala maka secara otomatis alat akan melakukan "Start up" sampai layar menampilkan tulisan "Ready". Disiapkan sampel yang akan diperiksa lalu ditempelkan pada alat penghisap sampai dasar tabung kemudian ditekan sampel bar sampai jarum masuk kembali dan melakukan pemeriksaan. Alat akan memproses sampel selama kurang lebih satu menit dan hasil pemeriksaan akan tampak pada layar dan secara otomatis tercetak pada berkas printer. Untuk mematikan alat, ditekan "shutdown" maka alat akan mencuci selama satu menit, setelah layar padam dimatikan alat dengan menekan switch utama yang terletak dibagian samping kanan alat.

Cara Manual

Hitung Jumlah Eritrosit:

Diisap darah EDTA dengan pipet thoma sampai pada garis 0,5. Kelebihan darah yang melekat pada ujung pipet dilap dengan kapas kering. Darah diencerkan dengan larutan hayem sambil menahan darah pada garis tanda tersebut, larutan hayem diisap sampai tanda 101. Pipet diangkat kemudian ujung pipet ditutup dengan jari lalu dilepaskan karet penghisap kemudian homogenkan selama 15-30 detik. Cairan dalam tabung dibuang 3 tetes kemudian dimasukkan kedalam kamar hitung. Hitung eritrosit dalam 5 bidang eritrosit dengan pembesaran 40x.

Perhitungan :

a) Faktor pengenceran :

$$
\frac{101-1}{0,5}=200 \times
$$

b) Faktor perkalian :

$$
\begin{aligned}
\text { LUAS 1 KS } & =\mathrm{P} \times \mathrm{L} \times \mathrm{T}=\frac{1}{5} \times \frac{1}{5} \times \frac{1}{10} \\
& =\frac{1}{250} \\
\text { LUAS } 5 \mathrm{KS} & =5 \times \frac{1}{250}=\frac{5}{250}=\frac{1}{50}
\end{aligned}
$$




$$
\frac{50}{1} \times 200=10.000
$$

c) Jumlah Eritrosit $=N \times 10.000$

Pemeriksaan hematokrit:

Diisi tabung mikrokapiler yang

khusus dibuat untuk penetapan mikrohematokrit dengan darah EDTA. Kemudian ditutup ujung tabung dengan bahan penutup khusus. Dimasukkan tabung mikrokapiler itu kadalam tabung sentrifuge khusus yang mencapai kecepatan besar, yaitu lebih dari 16.000 rpm (centrifuge mikrohematokrit). Diputar selama 3-5 menit khusus.

Pemeriksaan kadar Hb:

Dimasukkan 5 tetes HCL 0,1 N kedalam tabung pengencer hemometer sampai tanda 2 pada alat. Diisap darah EDTA dengan pipet hemoglobin sampai tanda garis 20 ul. Dihapus darah yang melekat pada sebelah luar ujung pipet. Darah dialirkan kedalam tabung yang sudah terisi HCL 0,1 N kemudian homogenkan. Ditambahkan aquadest setetes demi setetes, tiap kali diaduk dengan batang pengaduk. Lalu dibandingkan dengan larutan standar dalam tabung pada tempat yang terang. Baca kadar $\mathrm{Hb}$ dengan gram/100 ml darah.

Cara Kerja :

Pembuatan Preparat Basil Tahan Asam (BTA).

Membuat sediaan dari sputum dengan ukuran lebar $2 \mathrm{~cm}$ dan panjang 3 $\mathrm{cm}$ yang diberi label/kode sesuai nomor identitas pasien dengan menggunakan ose/lidi yang sudah disiapkan, Difiksasi diatas api bunsen/spiritus sebanyak 3 kali. Preparat yang sudah disiapkan, difiksasi diatas lampu spiritus sebanyak
3 kali, Ditetesi karbol fuchsin $1 \%$ kemudian dipanaskan jangan sampai mendidih, cukup dengan menguap saja, Dibiarkan selama 5 menit, dibilas preparat dengan aquadest, Dilunturkan dengan HCL-Alkohol 3\% selama 3 menit, kemudian dibilas kembali dengan air mengalir, Kemudian ditetesi dengan larutan methylene blue selama 30 detik, dibilas dengan air mengalir, dibiarkan preparat mengering.

Cara Pembacaan Basil Tahan Asam

Cara pembacaan Kuman BTA ini menggunakan Mikroskop dengan lensa objektif pembesaran 100x dengan oli Imersi,Tidak ditemukan BTA dalam 100 LP, disebut negatif,Ditemukan 1 9 BTA dalam 100 LP, ditulis jumlah kuman yang Ditemukan,Ditemukan 10 - 99 BTA dalam 100 Lp, disebut + atau (1+),Ditemukan 1 - 10 Bta dalam $1 \mathrm{LP}$, disebut ++ atau (2)minimal dibaca 50 LP, Ditemukan > 10 BTA dalam $1 \mathrm{LP}$, disebut +++ atau $(3+)$, minimal dibaca 20 LP.

Analisis data

Data dianalisis dengan uji korelasi pearson untuk melihat hubungan dengan pengolahan data dilakukan dengan menggunakan komputer dengan Software Program SPSS For Windows Versi 19,0.

$$
\text { Korelasi }=r_{x y}=\frac{\sum\left(x_{i}-\bar{x}\right)\left(y_{i}-\bar{y}\right)}{\sqrt{\sum\left(x_{i}-\bar{x}\right)^{2}} \cdot \sqrt{\sum\left(y_{i}-\bar{y}\right)^{2}}}
$$

\section{HASIL}

Berdasarkan hasil penelitian yang dilakukan di Balai Besar Kesehatan Paru Masyarakat Makassar pada tanggal 15 maret s/d 15 april 2017 terhadap 30 penderita tuberculosis sebagai berikut. 
Jurnal Media Analis Kesehatan, Vol. 8, No.2, November 2017 http://journal.poltekkes-mks.ac.id/ojs2/index.php/mediaanalis e-ISSN : 2621-9557

p-ISSN : 2087-1333

Tabel 1.

Hasil Pemeriksaan Indeks Eritrosit Pada Penderita Tuberculosis dengan gradasi 1+

\begin{tabular}{c|c|c|c}
\hline \multirow{2}{*}{ ID } & \multicolumn{3}{c}{ Gradasi BTA 1+ } \\
\cline { 2 - 4 } & MCV & MCH & MCHC \\
\hline J5 & 85 & 28 & 33 \\
R4 & 88 & 28 & 32 \\
J14 & 76 & 24 & 32 \\
J22 & 24 & 78 & 24 \\
R4 & 81 & 26 & 33 \\
6 & 84 & 25 & 30 \\
R5 & 87 & 29 & 33 \\
J1 & 86 & 27 & 31 \\
J31 & 77 & 24 & 31 \\
7 & 80 & 25 & 32 \\
18 & 81 & 26 & 33 \\
J29 & 85 & 25 & 29 \\
R7 & 91 & 29 & 32 \\
R2 & 83 & 26 & 31 \\
6 & 83 & 28 & 33 \\
Rerata & 79.40 & 29.87 & 31.27 \\
Std.Deviasi & 15.84 & 13.42 & 2.34 \\
Maks & 91 & 78 & 33 \\
Min & 24 & 24 & 24 \\
\hline
\end{tabular}

Tabel 2.

Hasil Pemeriksaan Indeks Eritrosit Pada Penderita Tuberculosis dengan gradasi 2+

\begin{tabular}{cccc}
\hline ID & \multicolumn{3}{c}{ Gradasi BTA 2+ } \\
\cline { 2 - 4 } & MCV & MCH & MCHC \\
\hline J21 & 81 & 28 & 31 \\
J5 & 84 & 28 & 34 \\
15 & 79 & 25 & 31 \\
25 & 85 & 27 & 31 \\
R9 & 76 & 24 & 31 \\
15 & 75 & 23 & 31 \\
17 & 80 & 22 & 29 \\
Rerata & 80.00 & 25.29 & 31.14 \\
Std.Deviasi & 3.74 & 2.43 & 1.46 \\
Maks & 85 & 28 & 34 \\
Min & 75 & 22 & 29
\end{tabular}


Sumber : Data Primer 2017

Berdasarkan hasil analisis dekriptif penderita tuberculosis 2+, tampak bahwa nilai rerata MCV yang dimiliki oleh responden 2+ sebesar 80,00, Std. Deviasi 3,74, Nilai maksimum 85,00, Nilai minimum 75 . Selanjutnya nilai rerata $\mathrm{MCH}$ yang dimiliki oleh responden 2+ sebesar 25,29, Std. Deviasi 2,43, Nilai maksimum 28,00, Nilai minimum 22. Sedangkan nilai rerata $\mathrm{MCHC}$ yang dimiliki oleh responden 2+ sebesar 31,14, Std. Deviasi 1,46, Nilai maksimum 34,00, Nilai minimum 29.

Tabel 3.

Hasil Pemeriksaan Indeks Eritrosit Pada Penderita Tuberculosis dengan gradasi

\begin{tabular}{cccc}
\hline \multicolumn{4}{c}{$3+$} \\
\cline { 2 - 4 } ID & Gradasi BTA 3+ \\
\cline { 2 - 4 } MCV & MCH & MCHC \\
R7 & 86 & 79 & 25 \\
21 & 90 & 26 & 32 \\
R6 & 86 & 25 & 29 \\
R5 & 80 & 24 & 31 \\
R6 & 86 & 25 & 30 \\
R1 & 88 & 25 & 29 \\
J8 & 87 & 26 & 32 \\
Rerata & 79.25 & 32.00 & 29.75 \\
Std.Deviasi & 17.80 & 19.00 & 2.25 \\
Maks & 90 & 79 & 32 \\
Min & 36 & 24 & 25 \\
\hline \multicolumn{3}{c}{ Sumber : Data Primer 2017}
\end{tabular}

Berdasarkan hasil analisis dekriptif penderita tuberculosis 3+, tampak bahwa nilai rerata MCV yang dimiliki oleh responden $3+$ sebesar 79,25 , Std. Deviasi 17,80, Nilai maksimum 90,00, Nilai minimum 36. Selanjutnya nilai rerata $\mathrm{MCH}$ yang dimiliki oleh responden $3+$ sebesar 32,00, Std. Deviasi 19,00, Nilai maksimum 79,00, Nilai minimum 24. Sedangkan nilai rerata $\mathrm{MCHC}$ yang dimiliki oleh responden $3+$ sebesar 29,75, Std. Deviasi 2,25, Nilai maksimum 32,00, Nilai minimum 25.

\section{PEMBAHASAN}

Bakteri tahan asam adalah bakteri yang dapat mengikat karbolfuksin (fuksin basa larut dalam campuran air-alkohol-fenol) meskipun terjadi dekolorisasi dengan asam $\mathrm{HCl}$ dalam alkohol. Bakteri tahan asam kaya akan lipid, mencakup asam mikolat (asam lemak rantai panjang C78-C96), lilin dan fosfatida. Panjangnya struktur lipid ini mempengaruhi tingkat ketebalan lpid yang menyebabkan bakteri tahan asam. Kelompok bakteri tahan asam adalah Mycobacterium dan Actinomycetes. Kedua kelompok ini jika diwarnai dengan kabol fuksin berwarna merah (Brooks et al., 1996). Menurut Misnadiarly dan Simanjuntak (1993), kelompok Mycobacterium tahan asam 
diantaranya adalah M. cansai, M. gastri, M. smegmatis, M. terra complek, M. chelonei, M. Simiae, M. scrofulaccum dan M. tuberculosis.

Sumber penularan adalah penderita TBC BTA Positif. Pada waktu batuk atau bersin, penderita menyebarkan kuman ke udara dalam bentuk droplet ( percikan dahak ). Droplet mengandung kuman dapat bertahan di udara pada suhu kamar selama beberapa jam. Orang dapat terinfeksi kalau droplet tersebut terhirup kedalam saluran pernafasan. Setelah kuman TBC masuk kedalam tubuh manusia melalui pernafasan, kuman TBC tersebut dapat menyebar dari paru kebagian tubuh lainnya, melalui system peredaran darah, system saluran limfe, saluran nafas, atau penyebaran langsung ke bagianbagian tubuh lainnya. Selama penderita pada dahaknya masih terdapat BTA positif maka penderita tersebut dapat menularkan penyakitnya pada orang lain.

Kelainan hematologi pada pasien tuberkulosis dapat disebabkan karena infeksi tuberkulosis, efek samping OAT atau kelainan dasar hematologis yang sudah ada sebelumnya. Kelainan hematologi tersebut dapat menjadi pertimbangan dalam pemilihan OAT, serta pemeriksaan penunjang untuk menilai respon pengobatan.

Nilai eritrosit rata-rata (Mean Corpuscular Volume) atau disebut juga Indeks Eritrosit merupakan bagian dari pemeriksaan laboratorium hitung darah lengkap yang memberi keterangan mengenai banyaknya hemoglobin (hb) per eitrosit. Biasanya digunakan dalam mengklassifikasi anemia dan untuk membantu mendiagnosis penyebab anemia. Volume sel rerata (MCV), hemoglobin sel rerata $(\mathrm{MCH})$, konsentrasi Hemoglobin sel rerata (MCHC) dihitung dari Hematokrit(PCV), perkiraan hemoglobin, dan hitung sel darah merah.

Berdasarkan hasil penelitian menunjukkan bahwa jumlah indeks eritrosit pada penderita tuberculosis di BBKPM Makassar yaitu dengan rerata MCV sebanyak 79,55, MCH 29,05, dan MCHC 30,72.

MCV mencerminkan volume rata-rata sel darah merah.Dengan perhitungan elektronik.MCV diukur secara langsung, tetapi MCV dapat dihitung dengan membagi hematokrit dengan hitung sel darah merah yang dinyatakan dalam juta per mikroliter dan dikali 1000. MCV ini dapat menentukan ukuran sel darah merah. Umumnya, ukuran sel darah merah dapat ditentukan dari pemeriksaan sediaan darah langsung dengan mikroskop. Namun, pemeriksaan dengan mikroskop sangat bergantung pada tingkat kemampuan orang yang melakukan pemeriksaan. Oleh karena itu, pemeriksaan MCV ini dapat membantu mengkonfirmasi hasil yang didapatkan pada pemeriksaan darah langsung melalui mikroskop. Nilai MCV yang rendah menunjukkan ukuran sel darah merah yang kecil (atau disebut dengan mikrositik), nilai MCV yang normal menunjukkan ukuran sel darah merah yang normal, dan nilai MCV yang tinggi menunjukkan ukuran sel darah merah yang besar (atau disebut dengan makrositik). Nilai tersebut dapat menentukan tipe anemia (kekurangan sel darah merah) berdasarkan ukuran sel darah merah tersebut. 
Berdasarkan hasil penelitian menunjukkan bahwa jumlah indeks eritrosit pada penderita tuberculosis di BBKPM Makassar yaitu dengan rerata MCV sebanyak 79,55, MCH 29,05, dan MCHC 30,72. MCV mencerminkan volume rata-rata sel darah merah.Dengan perhitungan elektronik.MCV diukur secara langsung, tetapi MCV dapat dihitung dengan membagi hematokrit dengan hitung sel darah merah yang dinyatakan dalam juta per mikroliter dan dikali 1000.

MCV ini dapat menentukan ukuran sel darah merah. Umumnya, ukuran sel darah merah dapat ditentukan dari pemeriksaan sediaan darah langsung dengan mikroskop. Namun, pemeriksaan dengan mikroskop sangat bergantung pada tingkat kemampuan orang yang melakukan pemeriksaan. Oleh karena itu, pemeriksaan MCV ini dapat membantu mengkonfirmasi hasil yang didapatkan pada pemeriksaan darah langsung melalui mikroskop. Nilai MCV yang rendah menunjukkan ukuran sel darah merah yang kecil (atau disebut dengan mikrositik), nilai MCV yang normal menunjukkan ukuran sel darah merah yang normal, dan nilai MCV yang tinggi menunjukkan ukuran sel darah merah yang besar (atau disebut dengan makrositik). Nilai tersebut dapat menentukan tipe anemia (kekurangan sel darah merah) berdasarkan ukuran sel darah merah tersebut

\section{KESIMPULAN}

Berdasarkan hasil penelitian diatas maka ditarik suatu kesimpulan yaitu :
1. Jumlah indeks eritrosit pada penderita tuberculosis di BBKPM Makassar yaitu dengan rerata MCV sebanyak 79,55, MCH 29,05, dan MCHC 30,72.

2. Ada hubungan indeks eritrosit pada penderita tuberculosis dengan gradasi $1+$.

3. Ada hubungan indeks eritrosit pada penderita tuberculosis dengan gradasi $2+$.

4. Ada hubungan indeks eritrosit pada penderita tuberculosis dengan gradasi $3+$.

5. Ada hubungan indeks eritrosit pada penderita tuberculosis dengan gradasi basil tahan asam.

\section{SARAN}

Ada pun saran-saran dalam penelitian ini adalah sebagai berikut :

1. Perlu penelitian lanjutan untuk melihat hubungan gradasi basil tahan asam terhadap indeks eritrosit.

2. Pada penelitian selanjutnya dilakukan penelitian tentang sejauh mana pengaruh indeks eritrosit dan jenis Anemianya terhadap penderita TB.

\section{DAFTAR PUSTAKA}

Amaylia Oehadian, 2003. Aspek Hematologi Tubeculosis. SubBagian Hematologi-Onkologi Medik SMF Penyakti Dalam RS Perjan Hasan Sadikin/FK UNPAD. Bandung.

Brugnara C. Iron deficiency and erythropoiesis: new diagnostic approaches. Clin Chem 2003;49:15738.

Flemming AF de silva PS.Haematological Diseases in the tropics.in :Cook GC,Zumlz AI,eds.manson's 
Tropical Diseases,21 st ed.Edinburg, saunders, 2003:224.

Forbes A Betty, Daniel F Sahm, Alice S Weissfeld. Bailey \& Scott's. Diagnostic Microbiology. Twelfth edition. China: Mosby Elsevier.2007.p 478508

Handayani, Andi S. 2008.Asuhan KeperawatanPada Klien Dengan Gangguan Sistem Hematologi. Dian Rakyat. Jakarta.

Hizira, S. 2008. Hubungan Pola Konsumsi dan Status Gizi penderita Tuberculosis

Kusnadi, 2010. Hubungan Jenis Leukosit dengan Kejadian Tuberculosis di Balai Besar Kesehatan Paru Masyarakat Makassar.Makassar.

Misnadiarly.2006. Penyakit Infeksi TB paru dan Ekstrak Paru.Edisi I. Pustaka Populer Obor, Jakarta.

Purnasari, Galih, 2011. Tuberkulosis.

Penelitian Fakultas

Kedokteran : Universitas Diponegoro

Sarwono W. 1995.Ilmu Penyakit Dalam.Bagian Ilmu Penyakit
Dalam FK,UI. RSUP

Nasional Cipto Mangunkusumo,Hal: 203211.

Sugiyono. 2003. Statistika Untuk Penelitian. CV Alfabeta. Bandung

Wahyudi N, 2009. Pusat data dan Jurnal"Hubungan karakteristik tersangka TBC dengan TBC paru BTA positif di puskesmas Tanon relationship between the characteristic of Tuberculosis suspect and pulmonary Tuberculosis with positive acid-fast bacilli in puskesmasTanon (2009Skripsi). Makassar.

Wilks D, 1995. Mycobacteria In The Infection Disease. Blackwell Science Ltd, Oxford.

Yoga TA,.1994.Tuberculosis Paru Masalah dan Penanggulangannya.Universi tas Indonesia, Jakarta.

Oyer RA,SchlossbergD.Hematologic Changes in Tuberculosis..In:Schlossberg D.ed.tuberculosis, $3^{\text {rd }}$ Ed.newYork,Springerverlag, 1994:257-263. 